\title{
Ultimate Metastable Solubility of Boron in Diamond: Synthesis of Superhard Diamondlike $\mathrm{BC}_{5}$
}

\author{
Vladimir L. Solozhenko* and Oleksandr O. Kurakevych \\ LPMTM-CNRS, Université Paris Nord, F-93430 Villetaneuse, France \\ Denis Andrault \\ LMV, Université Blaise Pascal, F-63000 Clermont-Ferrand, France \\ Yann Le Godec \\ IMPMC, Université P\&M Curie, F-75015 Paris, France \\ Mohamed Mezouar \\ European Synchrotron Radiation Facility, F-38043 Grenoble, France
}

(Received 13 October 2008; published 9 January 2009)

\begin{abstract}
Here, we report the synthesis of cubic $\mathrm{BC}_{5}\left(\mathrm{c}-\mathrm{BC}_{5}\right)$, the diamondlike $\mathrm{B}-\mathrm{C}$ phase with the highest boron content ever achieved, at $24 \mathrm{GPa}$ and about $2200 \mathrm{~K}$, using both a laser-heated diamond anvil cell and large-volume multianvil apparatus. The synthesized phase is low compressible (bulk modulus of $335 \mathrm{GPa})$, conductive, and exhibits extreme Vickers hardness (71 GPa), unusually high for superhard materials fracture toughness $\left(9.5 \mathrm{MPa} \mathrm{m}^{0.5}\right)$, and high thermal stability (up to $1900 \mathrm{~K}$ ); this makes it an exceptional superabrasive and promising material for high-temperature electronics.
\end{abstract}

DOI: 10.1103/PhysRevLett.102.015506

PACS numbers: 61.66.Fn, 61.05.cp, 62.50.-p

Diamond has found a wide variety of applications in modern science and technology due to its unique properties, such as extreme hardness, high thermal conductivity, wide band gap, high electron and hole mobility [1]. At the same time, it is nonresistant to oxidation and reactive with ferrous metals. The growing demand for advanced superhard materials in cutting and shaping hard metals and ceramics [2], as well as in electronic [3] and electrochemical [4] applications, has stimulated the search for novel diamondlike phases that are more thermally and chemically stable than pure diamond.

The traces of boron impurities change the electrical properties of diamond from an insulator into a semiconductor $[3,4]$. Moreover, boron-doped diamond was reported to be a type-II superconductor with transition temperature $T_{c} \approx 5 \mathrm{~K}$ [5], while heavily boron-doped diamond ( $\geq 20$ at\% B) is predicted to be a superconductor with very high, up to $55 \mathrm{~K}, T_{c}$ [6]. However, only very limited amount of boron $(\sim 2$ at $\%)$ can be introduced into diamond lattice by common methods of thermal chemical vapor deposition and high-pressure synthesis. The limiting concentration of boron that can be incorporated into diamond structure has not been established yet, although under extreme pressure-temperature conditions, this content could be significantly increased. Since all B-C materials show higher resistance to oxygen and ferrous metals than similar carbon materials [7], the diamondlike B-C phases with high boron content are expected to combine the best properties of the elements including advanced electrical and optical properties, very high hardness, and high thermal and chemical stability.
A number of graphitelike B-C phases of different stoichiometry (so called boron-substituted graphites with boron content up to 50 at $\%$ ) have been synthesized by thermal chemical vapor deposition [8]. These materials should be perfect precursors for diamondlike B-C phases; however, their high-pressure, high-temperature behavior has not been well understood so far. Recent experiments on graphitelike $\mathrm{BC}_{3}$ showed that at $20 \mathrm{GPa}$ and $2200 \mathrm{~K}$ in a multianvil press, the phase decomposes into the mixture of boron-doped diamond ( $\sim 1.8$ at\% of boron) and boron carbide [9]. Very recently, phase segregation of graphitelike $\mathrm{BC}_{1.6}$ into a mixture of diamond, boron carbide, and elemental boron was observed in a diamond anvil cell at $45 \mathrm{GPa}$ and $2230 \mathrm{~K}$ [10]. Hence, all previous attempts to synthesize diamondlike B-C phases with boron concentration higher than $\sim 2$ at $\%$ have failed.

In the present study, we have performed a systematic investigation of phase transformations of turbostratic graphitelike $\mathrm{BC}_{x}$ phases $\left(\mathrm{t}-\mathrm{BC}_{x}\right)$ at pressures up to $25 \mathrm{GPa}$ and temperatures up to $2500 \mathrm{~K}$ with the aim to establish the ultimate boron solubility in diamond and synthesize diamondlike B-C phase(s) with a high boron content.

Our in situ studies of t-BC and $\mathrm{t}-\mathrm{BC}_{3}$ in the 3-7 GPa pressure range using multianvil system MAX80 and energy-dispersive $\mathrm{x}$-ray diffraction with synchrotron radiation at HASYLAB-DESY have shown that neither phase undergoes any transformation up to $2000 \mathrm{~K}$.

In situ experiments at higher pressures and temperatures have been conducted at ID30 and ID27 beam lines of the European Synchrotron Radiation Facility using laser- 
heated diamond anvil cell (DAC) and angle-dispersive $\mathrm{x}$-ray diffraction. At pressures above $20 \mathrm{GPa}$ in the 2000-2500 K range, $\mathrm{t}-\mathrm{BC}_{x}$ phases $(1 \leq x \leq 4)$ decompose into boron-doped diamond (1-2 at\% of boron) and boron carbides $\left(\mathrm{B}_{4} \mathrm{C}\right.$ and $\left.\mathrm{B}_{50} \mathrm{C}_{2}\right)$ that are accompanied by the formation of cubic B-C phases $\left(\mathrm{c}-\mathrm{BC}_{z}\right)$ with lattice parameters up to $2 \%$ higher than that of diamond [Fig. 1(a)]. The decrease of the maximal temperature in an experiment from 2500 down to $2000 \mathrm{~K}$ leads to a higher amount of forming $\mathrm{c}-\mathrm{BC}_{z}$. At the same time, the higher is the pressure, the lower is the starting temperature of $\mathrm{t}-\mathrm{BC}_{x}$ decomposition, especially in the case of the phases with high boron content. Thus, at $41 \mathrm{GPa}$, phase segregation of $\mathrm{t}-\mathrm{BC}$ and $\mathrm{t}-\mathrm{BC}_{1.5}$ was observed already at $1750 \mathrm{~K}$. Based on these results, one can conclude that synthesis of a pure cubic B-C phase corresponding to the ultimate solubility of boron in diamond may be expected only in the case of $\mathrm{t}-\mathrm{BC}_{x}$ precursors with relatively low boron content $(x \geq 5)$.

At room temperature, compression of turbostratic $\mathrm{BC}_{5}$ is accompanied by a pronounced decrease of intensities of the $00 l$ lines similar to that observed for turbostratic CBN solid solutions [11,12]. Upon compression to $24 \mathrm{GPa}$, these lines almost disappear [Fig. 1(b)]. Also, with increasing pressure, the profile of the two-dimensional 10 reflection becomes more symmetric, and the intensity of this line increases. These features, observed independently on the diffraction geometry in relation to the compression axis $[12,13]$, point to the reconstruction of the turbostratic graphitelike $s p^{2}$-layers into the disordered $s p^{3}$-structure,

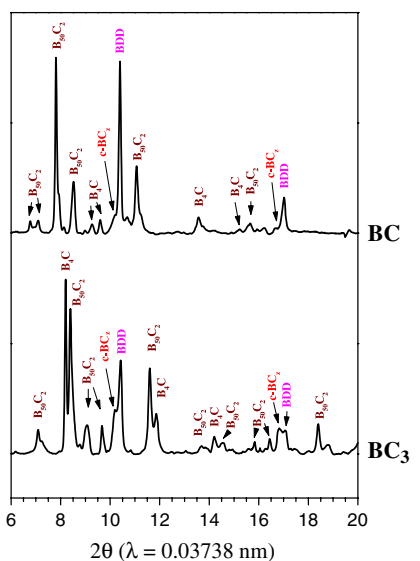

(a)

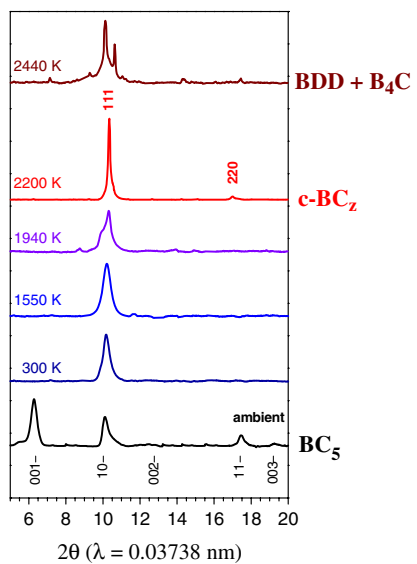

(b)
FIG. 1 (color online). (a) Representative diffraction patterns of the $\mathrm{BC}_{3}$ and $\mathrm{BC}$ samples quenched from $26 \mathrm{GPa}$ and $2400 \mathrm{~K}$. Both phases decompose into boron-doped diamond with $\sim 1.8$ at $\%$ of $\mathrm{B}(\mathrm{BDD})$, cubic $\mathrm{BC}_{z}$ phase (according to lattice parameters, $\mathrm{BC}_{9}$ and $\mathrm{BC}_{5}$ for starting $\mathrm{t}-\mathrm{BC}_{3}$ and $\mathrm{t}-\mathrm{BC}$, respectively), and boron carbides $\mathrm{B}_{4} \mathrm{C}$ and $\mathrm{B}_{50} \mathrm{C}_{2}$. (b) Typical laser-heating sequence of diffraction patterns of $\mathrm{BC}_{5}$ sample taken in situ at $24 \mathrm{GPa}$ and several temperatures. The bottom pattern corresponds to $\mathrm{t}-\mathrm{BC}_{5}$ at ambient conditions. previously reported for other graphitic phases of the B-C-N system $[12,14]$.

At $24.0 \mathrm{GPa}$, no change in the diffraction patterns of t-BC ${ }_{5}$ has been observed below $1550 \mathrm{~K}$ [Fig. 1(b)]. At higher temperatures, the profile of the only broad line of the pattern that is located in the region of 111 reflection of diamond shows the appearance of a fine structure. Finally, at $2200 \mathrm{~K}$, the formation of the cubic $\mathrm{BC}_{z}$ phase has been observed, and the diffraction pattern exhibits only 111, 220, and 311 lines of the cubic (or, to be precise, pseudocubic) lattice, which indicates that the sample contains a single crystalline phase. Since no amorphous phase has been observed in the quenched samples by both transmission electron microscopy and Raman spectroscopy, one can assume that the composition of the cubic phase is the same as that of the precursor, namely, $\mathrm{BC}_{5}$. The 1:5 boronto-carbon ratio has been additionally confirmed by electron energy loss spectroscopy (GIF2000, Gatan) and by electron microprobe analysis (Cameca SX-50, Camebax).

Being instantly heated up to $2440 \mathrm{~K}$ at the same pressure, the as-synthesized cubic phase undergoes the decomposition into boron-doped diamond $(\sim 2$ at $\%$ of boron according to the lattice parameter) and boron carbide $\mathrm{B}_{4} \mathrm{C}$ [Fig. 1(b)]. The relatively narrow temperature range $(\sim 200 \mathrm{~K})$ of the $\mathrm{c}-\mathrm{BC}_{5}$ formation clearly indicates the metastable character of this phase; e.g., its slight overheating leads to the phase segregation into more thermodynamically stable boron-doped diamond and boron carbides. Thus, the value of 16 at $\%$ of boron may be considered as a concentration limit of existence of metastable diamondlike B-C phases. These metastable phases do not participate in the phase equilibria in the B-C system at high pressures and temperatures, while the $p-T-x$ domain of their formation is determined by the boron concentration dependencies of the activation barriers for $\mathrm{t}-\mathrm{BC}_{x}$ and $\mathrm{c}-\mathrm{BC}_{x}$ decomposition, and $\mathrm{t}-\mathrm{BC}_{x}$ into $\mathrm{c}-\mathrm{BC}_{x}$ transformation.

According to the transmission electron microscopy (JEM 2010HR, JEOL), cubic $\mathrm{BC}_{5}$ quenched down to ambient conditions occurs as nanocrystalline aggregates with clearly visible but very small (average size: 10-15 nm) grains. The three strongest diffraction rings of the selected area electron diffraction (SAED) patterns, i.e., 111, 220, and 311 , allowed us to evaluate the lattice parameter of cubic $\mathrm{BC}_{5}$ as $a=0.359(7) \mathrm{nm}$. The more precise value of lattice parameter was established by angle-dispersive $\mathrm{x}$-ray diffraction with synchrotron radiation and was found to be $a=0.3635 \pm 0.0006 \mathrm{~nm}$, which is larger than those of both diamond $(0.35667 \mathrm{~nm}$ for single crystal diamond according to JCPDS No. 6-0675, and $0.35688 \mathrm{~nm}$ for nanodiamond [15]) and cubic boron nitride $(0.36158 \mathrm{~nm}$, JCPDS No. 35-1365). This is consistent with the fact that the $\mathrm{B}-\mathrm{C}$ bond is longer than $\mathrm{C}-\mathrm{C}$ and $\mathrm{B}-\mathrm{N}$ bonds [16] due to the weakened bonding caused by the electron-deficit character of the B atoms. 
The $a$-value for cubic $\mathrm{BC}_{5}$ expected from ideal mixing (Vegard's law) between diamond and "diamondlike boron" ( $a=0.404 \mathrm{~nm}$ corresponding to the B-B bond length of $0.175 \mathrm{~nm}$ [16]) is $0.3646 \mathrm{~nm}$ that is in good agreement with the experimental value [Fig. 2(a)]. The theoretical simulations performed by Lowther for hypothetical diamondlike boron-carbon structures [17] have also shown a satisfactory correspondence between calculated lattice parameters of cubic $\mathrm{BC}$ and $\mathrm{BC}_{3}$ and the Vegard law [see Fig. 2(a)]. The ideal mixing approach has allowed us to evaluate the compositions of quenched $\mathrm{c}-\mathrm{BC}_{z}$ phases formed during phase segregation of $\mathrm{t}-\mathrm{BC}_{x}$ $(x=1-5)$ at pressures above $20 \mathrm{GPa}$ and various temperatures [inset of Fig. 2(a)]. Thus, one can conclude that there exists a continuous series of $\mathrm{c}-\mathrm{BC}_{z}$ solid solutions (between 0 and 16 at $\%$ of $\mathrm{B}$ ), and $\mathrm{c}-\mathrm{BC}_{5}$ corresponds to the metastable ultimate solubility of boron in diamond.

The Raman spectrum (Dilor $X Y$ system, $514.5 \mathrm{~nm} \mathrm{Ar}^{+}$ ion laser) of cubic $\mathrm{BC}_{5}$ [Fig. 2(b)] is different from that of pure diamond (one prominent $\Gamma_{25}^{\prime}$ band at $\sim 1332 \mathrm{~cm}^{-1}$ ), but is very similar to the spectrum of boron-doped diamond ( $\sim 2$ at\% B) [18]. To date, the Raman spectra of such phases are not well understood. The comparison of the Raman data with the dispersion curves for phonons in diamond [19] shows that all observed band frequencies are very close to that of diamond. The appearance of new active modes may be attributed to a translation disordering in diamondlike structure due to the boron incorporation in the structure, when the Raman selection rules fail and we observe a phonon density of state. In addition to diamond modes, some local vibrations corresponding to the B-C and B-B (due to boron coupling in structure) bondings may

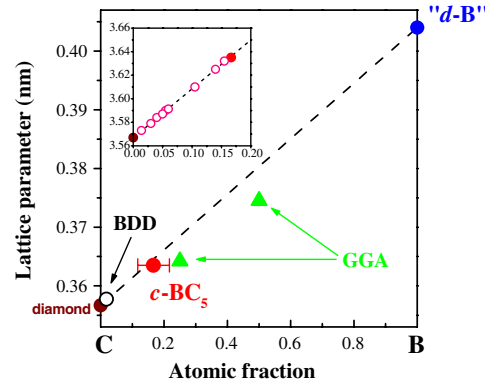

(a)

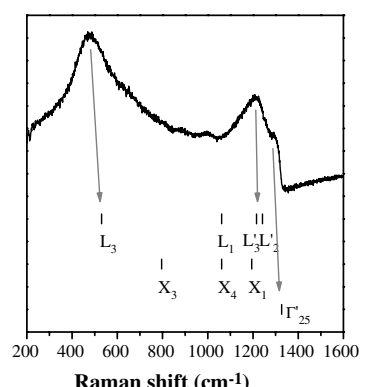

(b)
FIG. 2 (color online). (a) Lattice parameters of boronsubstituted diamonds versus boron content. The dashed line represents Vegard's law, while the symbols show the result of present work (circle with error bar) in comparison with other experimental (circles) [9] and theoretical (triangles [17]) data. The open circles in the inset show the lattice parameters and ideal mixing estimate for compositions of quenched $\mathrm{c}-\mathrm{BC}_{z}$ phases formed during phase segregation of $\mathrm{t}-\mathrm{BC}_{x}(x=1-5)$ at $p-T$ conditions under study. (b) Raman spectrum of cubic $\mathrm{BC}_{5}$ at ambient conditions (514.5 nm excitation wavelength). The vertical bars represent the phonon frequencies observed by inelastic neutron scattering in pure diamond [19]. appear [18]. The electron-deficit character of these bondings should give rise to the interaction of phonons with a continuum of charge carriers; that could lead to the appearance of additional modes. Thus, the Raman spectrum is consistent with a diamondlike structure of the synthesized phase, and one may suggest that the boron distribution in c-BC $\mathrm{C}_{5}$ is similar to that of known $B$-doped diamonds with lower (1-2 at\%) boron concentration.

The $300-\mathrm{K}$ equation of state of cubic $\mathrm{BC}_{5}$ has been measured up to $40 \mathrm{GPa}$ in three independent runs. Nitrogen and 4:1 methanol-ethanol mixture have been used as a pressure medium to maintain quasihydrostatic conditions. The fit of the two-parameter Birch equation of state to the experimental data have given the values of bulk modulus $B_{0}=335 \pm 8 \mathrm{GPa}$ and its first pressure derivative $B_{0}{ }^{\prime}=4.5 \pm 0.6$, with the zero-pressure cell volume $V_{0}=0.04802 \pm 0.00005 \mathrm{~nm}^{3}$. The bulk modulus of cubic $\mathrm{BC}_{5}$ is smaller than those of diamond (446 GPa [20]) and cBN (377 GPa [21]), that is expected from a weaker bonding between $\mathrm{B}$ and $\mathrm{C}$ atoms in comparison to the $\mathrm{C}-\mathrm{C}$ and $\mathrm{B}-\mathrm{N}$ bondings.

To synthesize a bulk sample of $\mathrm{c}-\mathrm{BC}_{5}$ for hardness measurements, etc., we have performed a number of quenching experiments in a large-volume V7 ParisEdinburgh press combined with a " $T$-cup" multianvil stage [22] under the same $p, T$-conditions as for the DAC synthesis. We have succeeded to obtain two singlephase millimeter-sized bulk samples in the experiments when the precursor was not overheated. X-ray powder diffraction analysis, transmission electron microscopy, and electron energy loss spectroscopy have revealed that the synthesized phase is identical to the cubic $\mathrm{BC}_{5}$ observed in the DAC experiments.

The Vickers hardness measurements of bulk cubic $\mathrm{BC}_{5}$ under loads from 1 to $20 \mathrm{~N}$ have shown that the calculated microhardness decreases with the load and reaches its asymptotic value at 2-3 N. As recommended for hard and brittle materials [23], the sample hardness was estimated in the asymptotic-hardness region as $H_{V}=$ 71(8) GPa. This value is close to the Vickers hardness of nanostructured bulk cubic $\mathrm{BC}_{2} \mathrm{~N}$, the second-hardest known phase [11], and is in excellent agreement with the value predicted in the framework of the thermodynamic model of hardness, i.e., 70.6 GPa [24]. Under the 10 and 20-N loads, we have observed the cracks that allowed us to calculate the reliable load-independent value of fracture toughness, $K_{\mathrm{Ic}}=9.5(2.5) \mathrm{MPam}^{1 / 2}$, by the method described in Ref. [25]. Nanoindentation measurements have also shown the extremely high value of $\mathrm{c}-\mathrm{BC}_{5}$ nanohardness, i.e., 73(7) GPa. In Table I, we compare c- $\mathrm{BC}_{5}$ with diamond, $\mathrm{cBN}$, and boron carbide in terms of mechanical properties [25-28].

The thermal stability of cubic $\mathrm{BC}_{5}$ at ambient pressure in a nonoxidizing environment has been in situ studied by $\mathrm{x}$-ray diffraction with synchrotron radiation using MAX80 
TABLE I. Mechanical properties of superhard phases of the BC-N system.

\begin{tabular}{lccc}
\hline \hline Phase & $\begin{array}{c}\text { Vickers hardness } \\
{[\mathrm{GPa}]}\end{array}$ & $\begin{array}{c}\text { Nanohardness } \\
{[\mathrm{GPa}]}\end{array}$ & $\begin{array}{c}\text { Fracture toughness } \\
{\left[\mathrm{MPa} \mathrm{m}{ }^{0.5}\right]}\end{array}$ \\
\hline $\mathrm{c}-\mathrm{BC}_{5}$ & 71 & 73 & 9.5 \\
$\mathrm{~B}_{4} \mathrm{C}^{\mathrm{a}}$ & $38^{\mathrm{b}}$ & & $3-4^{\mathrm{b}}$ \\
$\mathrm{cBN}^{\mathrm{c}}$ & $62^{\mathrm{b}}$ & $55^{\mathrm{b}}$ & $2.8^{\mathrm{b}} ; 6.8^{\mathrm{d}}$ \\
$\mathrm{c}-\mathrm{BC}_{2} \mathrm{~N}^{\mathrm{e}}$ & $76^{\mathrm{d}}$ & $75^{\mathrm{d}}$ & $4.5^{\mathrm{d}}$ \\
diamond $^{\mathrm{f}}$ & $115^{\mathrm{b}}$ & & $5.3^{\mathrm{b}, \mathrm{d}}$ \\
\hline \hline
\end{tabular}

${ }^{\mathrm{a}}$ Refs. [26,27].

${ }^{\mathrm{b}}$ Single crystal, (111) face. Polycrystalline material.

${ }^{\mathrm{c}}$ Ref. [25].

${ }^{\mathrm{d}}$ Polycrystalline material.

${ }^{\mathrm{e}}$ Refs. [11,25].

${ }^{\mathrm{f}}$ Ref. [28].

system at HASYLAB-DESY. The sequence of the powder diffraction patterns taken in the course of $\mathrm{c}-\mathrm{BC}_{5}$ heating has shown that the phase is stable up to $1890 \mathrm{~K}$, while at higher temperatures, it decomposes into disordered graphite and amorphous boron and/or boron carbides. Hence, c- $\mathrm{BC}_{5}$ is about $500 \mathrm{~K}$ more thermally stable than nanocrystalline diamond with the same grain size [15]; that can be attributed to the increase of decomposition activation barrier due to the presence of boron in the diamondlike lattice.

The room temperature electrical resistivity of cubic $\mathrm{BC}_{5}$ was measured by the standard four-point probe dc technique combined with van der Pauw method, and was found to be $\sim 0.6 \Omega \cdot \mathrm{m}$, which is the typical value for semiconductors.

Thus, diamondlike $\mathrm{BC}_{5}$ phase that corresponds to the ultimate solubility of boron in diamond has been synthesized under well-controlled pressure-temperature conditions using a laser-heated diamond anvil cell. Wellsintered millimeter-sized bulks of nanostructured $\mathrm{c}-\mathrm{BC}_{5}$ have been produced in a large-volume multianvil press. The material exhibits extreme hardness and fracture toughness, and very high thermal stability, which makes cubic $\mathrm{BC}_{5}$ an exceptional superabrasive overcoming diamond. The fortunate combination of the electrical conductivity, band structure that is unusual for diamondlike phases due to electron deficiency of boron atoms, and high thermal stability will eventually allow the expansion of the boundaries of high-temperature electronics and electrochemistry at extreme conditions.

The authors thank A. Derré for supplying the graphitelike B-C materials, V. Richard for TEM-EELS studies, E. Calderon for resistivity measurements, L. Dubrovinsky for microprobe analysis, A. Richter and R. Ries for nanoindentation studies. This work was carried out during beam time allocated to proposals HS1693 and HS2341 at ID30/ ID27, ESRF, and was supported by the Agence Nationale de la Recherche (Grant No. ANR-05-BLAN-0141) and the "Mission Ressources et Compétences Technologiques" of the CNRS. Experiments at HASYLAB-DESY were supported by the GFZ-Potsdam under the MAX80 program.

*Author to whom correspondence should be addressed. vls@1pmtm.univ-paris13.fr

[1] The Nature of Diamonds, edited by E. G. Harlow (Cambridge University Press, New York, 1998).

[2] N. V. Novikov, J. Mater. Proc. Tech. 161, 169 (2005).

[3] J. Isberg et al., Science 297, 1670 (2002).

[4] T. Yano et al., J. Electrochem. Soc. 146, 1081 (1999).

[5] E. A. Ekimov et al., Nature (London) 428, 542 (2004).

[6] J. E. Moussa and M. L. Cohen, Phys. Rev. B 77, 064518 (2008).

[7] L. E. Jones and P. A. Thrower, Carbon 29, 251 (1991).

[8] T. Shirasaki et al., Carbon 38, 1461 (2000).

[9] V. L. Solozhenko, N. A. Dubrovinskaia, and L.S. Dubrovinsky, Appl. Phys. Lett. 85, 1508 (2004).

[10] P. V. Zinin et al., J. Appl. Phys. 100, 013516 (2006).

[11] V. L. Solozhenko et al., Appl. Phys. Lett. 78, 1385 (2001).

[12] V. L. Solozhenko and O. O. Kurakevych, Acta Crystallogr. Sect. B: Struct. Crystallogr. Cryst. Chem. 61, 498 (2005).

[13] V.L. Solozhenko et al., Solid State Commun. 137, 268 (2006).

[14] V.L. Solozhenko, O. O. Kurakevych, and A. Yu. Kuznetsov, J. Appl. Phys. 102, 063509 (2007).

[15] The nanodiamond with grain size of 10-20 $\mathrm{nm}$ has been synthesized by shockwave compression of highly ordered graphite.

[16] J. Emsley, The Elements (Clarendon Press, Oxford, 1991).

[17] J. E. Lowther, J. Phys. Condens. Matter 17, 3221 (2005).

[18] M. Bernard, C. Baron, and A. Deneuville, Diam. Relat. Mater. 13, 896 (2004).

[19] J. L. Warren, J. L. Yarnell, G. Dolling, and R. A. Cowley, Phys. Rev. 158, 805 (1967).

[20] Ph. Gillet et al., Phys. Rev. B 60, 14660 (1999).

[21] V. L. Solozhenko et al., Appl. Phys. Lett. 72, 1691 (1998).

[22] Y. LeGodec et al., High Press. Res. 25, 243 (2005).

[23] V. Brazhkin et al., Nature Mater. 3, 576 (2004).

[24] V. A. Mukhanov, O. O. Kurakevych, and V. L. Solozhenko, High Press. Res., 28, 531 (2008).

[25] V. L. Solozhenko, S. N. Dub, and N. V. Novikov, Diam. Relat. Mater. 10, 2228 (2001).

[26] F. Thevenot, J. Eur. Ceram. Soc. 6, 205 (1990).

[27] G. DeWith, J. Mater. Sci. 19, 457 (1984).

[28] N. V. Novikov and S. N. Dub, J. Hard Mater. 2, 3 (1991). 